\title{
HIV infection, seasonality and younger age predicting incident Bell's palsy among black South Africans
}

Dali Magazi ${ }^{1 *}$, Benjamin Longombenza², Siyazi Mda ${ }^{3}$, Kees Van der Meyden', Marcus Motshwane ${ }^{4}$, Mirabel Nanjoh ${ }^{5}$ and Olakunle Towobola ${ }^{6}$

\begin{abstract}
Background: Although South Africa (SA) is facing a high prevalence of HIV infection, there is no literature from this region on a link between Bell's palsy and HIV. The aim of this study was to identify the occurrence of Bell's palsy in relation to demographics, seasons and HIV status among black South Africans.

Methods: This retrospective cohort was conducted among adult black patients, without Bell's palsy in 2003, presenting to the neurology outpatients department at Dr. George Mukhari Academic hospital, Pretoria, South Africa, between 2004 (study baseline) and 2012 (end test). Gender, age, HIV status, and seasons were potential predictors of Bell's palsy using Cox regression model and Kaplan Meier curves.

Results: From the baseline of 1487 patients, 20.9\% $(n=311)$ experienced Bell's palsy onset by the end of the study. In univariate analysis, male gender $(\mathrm{RR}=2.195 \% \mathrm{Cl} 1.7-2.5 ; P<0.0001)$, age less than 30 years $(\mathrm{RR}=2.995 \% \mathrm{Cl} 2.4-$ 3.6; $P<0.0001)$, HIV seropositivity ( $\mathrm{RR}=2.995 \% \mathrm{Cl} 2.3-4.9 ; P<0.0001)$.

The highest incidence in winter $(30.3 \% n=136 / 450)$ vs. incidences during other seasons with Intermediate values during Summer $(25.3 \% n=136 / 450)$ and Autumn $(20.7 \% n=64 / 308)$ and the lowest incidence in Spring $(23.7 \% n=$ 16/353) $P<0.0001$ ) were predictors of Bell's palsy. In multivariate analysis at adjusting for gender, the most significant and independent predictors of incident Bell's palsy were HIV seropositivity (HR=6.3 95\% Cl 4.8-8.3; $P<$ $0.0001)$, winter ( $\mathrm{HR}=1.695 \% \mathrm{Cl} 1.2-2.1 ; P<0.0001)$ vs. other seasons, and younger age $<30$ years $(\mathrm{HR}=7.195 \% \mathrm{Cl}$ $5.6-9.1 ; P<0.0001)$ vs. older age groups.

Conclusion: Seasonality, younger age and HIV positivity are important and independent risk factors of Bell's palsy. Education and awareness programs on the possible effects of HIV and seasons on the development of Bell's palsy are necessary. This would lead to a better understanding and even a possible development of avoidance measures for this condition amongst young black South Africans.
\end{abstract}

Keywords: Bell's palsy, Seasons, HIV, Young age, Males, South Africa

\footnotetext{
* Correspondence: dmagazi@profmagazi.co.za

'Department of Neurology, Sefako Makgatho Health Sciences University, Pretoria, South Africa

Full list of author information is available at the end of the article
}

(C) The Author(s). 2020 Open Access This article is licensed under a Creative Commons Attribution 4.0 International License, which permits use, sharing, adaptation, distribution and reproduction in any medium or format, as long as you give appropriate credit to the original author(s) and the source, provide a link to the Creative Commons licence, and indicate if changes were made. The images or other third party material in this article are included in the article's Creative Commons licence, unless indicated otherwise in a credit line to the material. If material is not included in the article's Creative Commons licence and your intended use is not permitted by statutory regulation or exceeds the permitted use, you will need to obtain permission directly from the copyright holder. To view a copy of this licence, visit http://creativecommons.org/licenses/by/4.0/. The Creative Commons Public Domain Dedication waiver (http://creativecommons.org/publicdomain/zero/1.0/) applies to the data made available in this article, unless otherwise stated in a credit line to the data. 


\section{Background}

Bell's palsy is an acute idiopathic lower motor neuron facial palsy, not associated with pyramidal signs. The seasonal occurrence of Bell's palsy has been debated for more than two centuries, first suggested by Nicolaus Friedreich in 1798 [1]. This continues to be a matter for debate since there is no universal consensus as to whether there is even a link between Bell's palsy and the seasons. An experimental study whereby maxillofacial tissue was frozen showed an immediate malfunction of the facial nerve which recovered after several weeks, the conclusion being that low temperatures trigger facial paralysis [2]. Indeed, in some countries, incident Bell's palsy has been observed more during the cold months of winter than in the warm months of summer [3]. However, in European settings such as Turkey, Bell's palsy was found to mostly occur in spring and least in the winter months [4]. There is no published data on the relationship between seasons and Bell's palsy in SubSaharan Africa generally. HIV infection has however, been associated with Bell's palsy in the tropical countries with no reports in this regard from the Sahel countries [5-7]. Our clinical impression was that there seems to be a link between certain seasons and a surge in the occurrence of Bell's palsy in South Africa with its high prevalence of HIV infection. Therefore, the objective of this study was to determine whether demographics, seasons and HIV status among black South Africans play a role in the occurrence of Bell's palsy.

\section{Methods}

This retrospective cohort was conducted among adult black patients, without Bell's palsy in 2003, presenting to the neurology outpatient department at Dr. George Mukhari Academic hospital, Pretoria, South Africa, between 2004 (study baseline) and 2012. Gender, age, HIV status, and seasons were potential predictors of Bell's palsy. Bell's palsy was defined by an acute idiopathic (unilateral/ bilateral) peripheral facial weakness with no pyramidal signs. Younger and older ages were defined by median age of 30 years. Cold seasons included autumn / fall and winter, while warm seasons included spring and summer. Autumn was defined as a transitional season from summer leading to winter while spring was defined as a transitional season from winter leading to summer.

\section{Statistical analysis}

Categorical variables were presented as proportions (\%), while the continuous variable (age) was expressed as the median. In univariate analysis, relative risk (RR) of incident Bell's palsy and its 95\% confidence interval (CI) was calculated (Mantel- Haenszel test). In multivariate analysis, the Cox regression model was computed to quantify the association (hazards ratio $=\mathrm{HR}$ with its 95\% CI) between exposures to univariate potential risk factors, and the multivariate risk of Bell's palsy after adjusting for confounding factors. Differences between exposed and non-exposed arms were investigated and KaplanMeier survival curves were generated using the log rank test. $P$ - value $<0.05$ was regarded as statistically significant. The statistical software IBM * SPSS version 22 for Windows (IBM, Chicago, IL, USA) was used for all analyses.

\section{Results}

Table 1 shows a significant univariate association between male gender, younger age $<30$ years, HIV seropositivity, seasonality and incident Bell's palsy. There was a seasonal acrophase rhythm with a winter peak and nadir (trough) during spring, the second highest in Summer which in turn was followed by Autumn with intermediate incidences of Bell's palsy (Fig. 1). In multivariate (Cox regression) analysis adjusting for gender, the most significant and independent predictors of incident Bell's palsy were HIV seropositivity, winter season, and younger age $<30$ years. The survival distributions for the different levels of age (Fig. 2) and HIV status (Fig. 3) using the log rank test are demonstrated on Kaplan Meier curves.

A majority of HIV positive females with Bell's palsy were not on ARV treatment (60\%) whilst the inverse was true for males (60\% on ARV treatment). There were no abnormalities of cognition demonstrated (including learning, memory and attention) in all patients with Bell's palsy with no difference in mental performance between those on ARVs and ARV naïve patients.

Table 1 Univariate association between potential predictors and Bell's palsy.

\begin{tabular}{llll}
\hline Variable of interest & Incident $\mathbf{n}(\%)$ & Bell's palsy & $P$-value \\
\hline & & RR $(95 \% \mathrm{Cl})$ & \\
Gender & & & \\
$\quad$ Males & $138 / 415(33.3)$ & $2.1(1.7-2.5)$ & $<0.0001$ \\
$\quad$ Females & $173 / 1072(16.1)$ & & \\
Age groups & & & \\
$\quad<\mathbf{3 0}$ years & $162 / 402(40.3)$ & $2.9(2.4-3.6)$ & $<0.0001$ \\
$\geq \mathbf{3 0}$ years & $149 / 1085(13.7)$ & & \\
Seasons & & & \\
$\quad$ Autumn & $64 / 308$ & & \\
Winter & $136 / 450$ & & \\
Spring & $16 / 353$ & & \\
$\quad$ Summer & $95 / 376$ & & \\
HIV & & & \\
Positive & $225 / 711(31.6)$ & $2.9(2.3-3.6)$ & \\
Negative & $86 / 776(11.1)$ & & \\
\hline
\end{tabular}




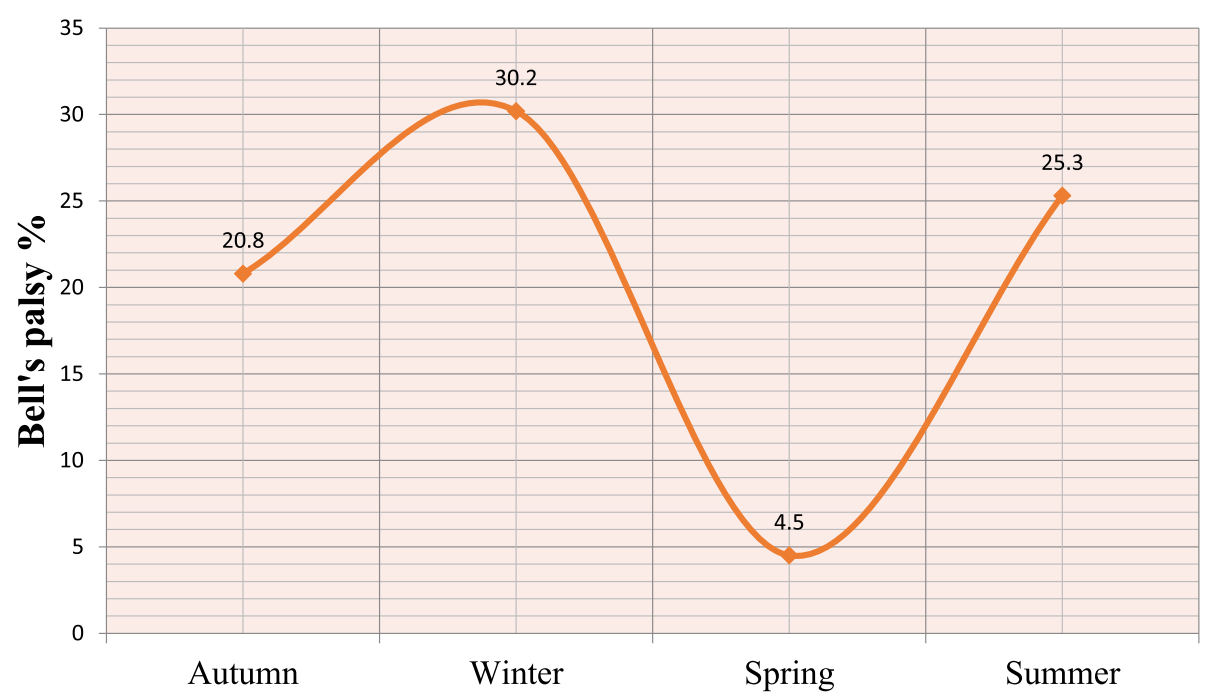

Fig. 1 Proportion of patients with Bell's palsy (\%) in relation to the seasons

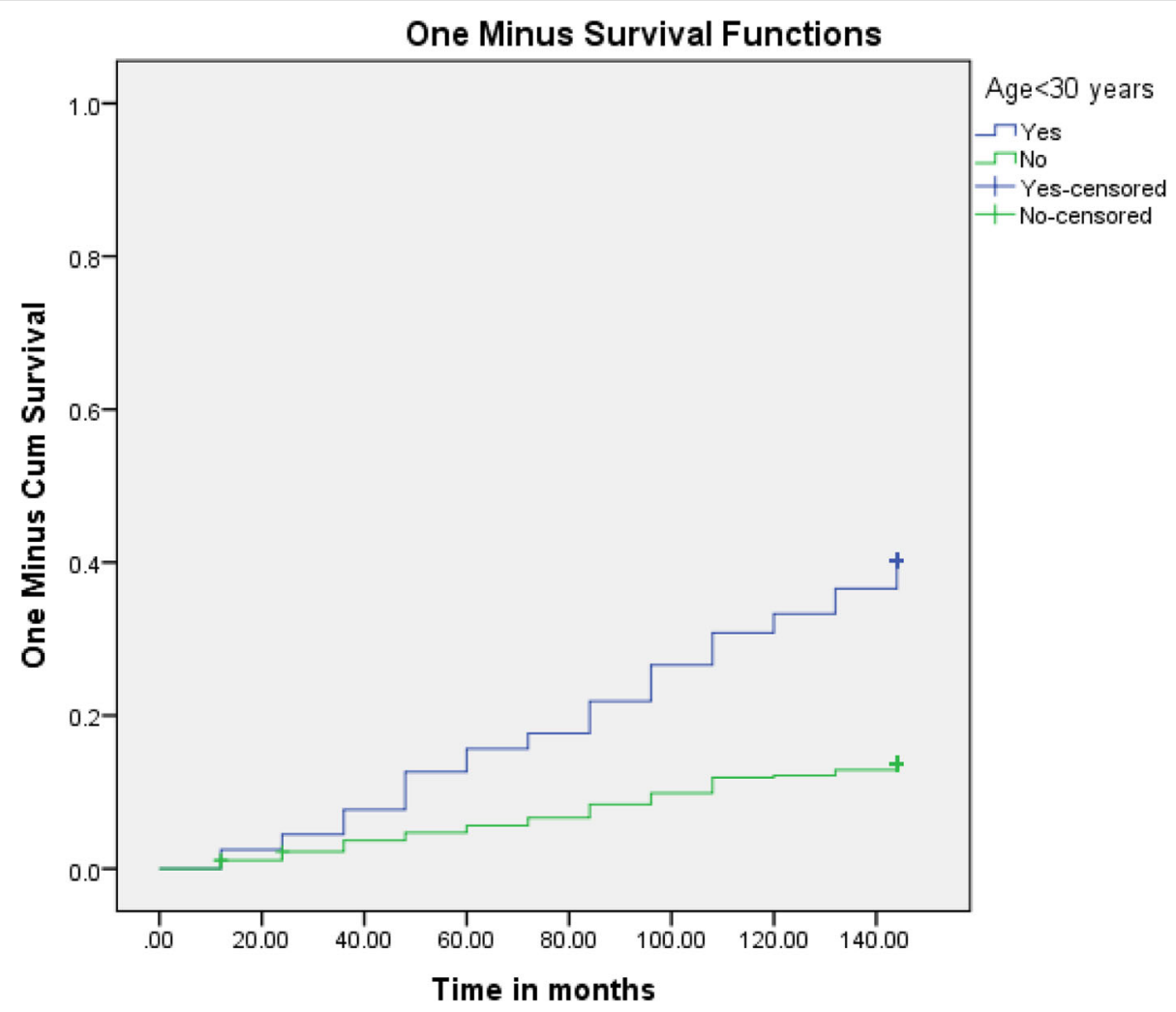

Fig. 2 Survival function for Bel's palsy incidence by age stratification 


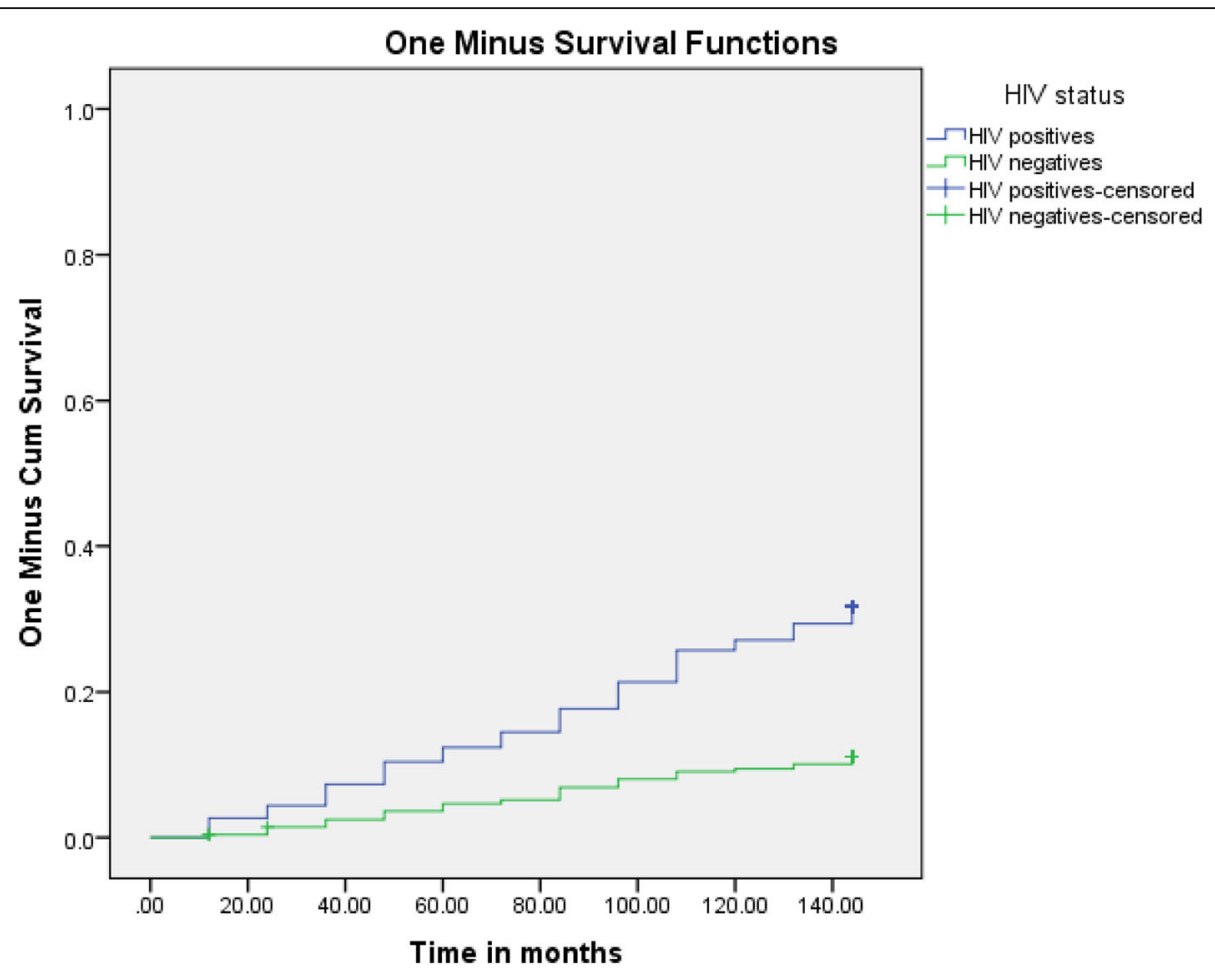

Fig. 3 Survival function to Incidence of Bell's palsy by HIV status

\section{Discussion}

The present study demonstrated univariate and multivariate associations between younger age, male gender, cold seasons, HIV infection, and incident Bell's palsy among black South African patients. These specific findings confirmed or disputed data reported from the literature as will be further elaborated.

\section{Age and Bell's palsy}

Bell's palsy can occur at any age but the question has been which age groups are most vulnerable to the condition. These vulnerable age groups could shed light further on the underlying pathophysiology of the condition. Our study showed a peak at the age less than 30 years. This is at variance with various previous studies in Europe and Asia which found Bell's palsy to peak in the fourth and fifth decade [8-11].

A study from the Benghazi region of Libya showed people above the sixth decade in age as being prone to Bell's palsy [3]. This was at variance with neighbouring Egypt whose findings showed the highest ages of involvement to be $40-49$ years [12]. A door-door survey in the rural part of the Cordillera province of Bolivia however, found similarly to the Libyan study with the prevalence of Bell's palsy increasing with age to peak at 65 years [13].

A Nigerian study showed the median age of occurrence to be 35.5 years, echoing studies in European settings [14]. A Togolese study of 150 individuals showed the average age of occurrence to be $31.4+/-$ 8.81 years [5]. A study with similar findings as our study was from Romania where the dominant age group of occurrence was $17-30$ years [15].

The narrative on age from these studies, worldwide is that Bell's palsy is a condition of the young and middleaged adult with the elderly being in the minority. A Brazilian study of 180 patients with Bell's palsy however, found two peaks, namely, third- fourth decade and sixth decade of life [16]. Some studies caution that when someone older than 60 years gets Bell's palsy, a secondary cause like diabetes mellitus could be the reason [8]. What puts the young adult at more risk than other age groups has not been previously explained.

\section{Gender}

There was a male preponderance on univariate analysis which however, didn't emerge on using the multivariate analysis in this study. A majority of studies on Bell's palsy demonstrate no difference in occurrence between the sexes $[8,17]$. There are studies however, that demonstrated a difference in occurrence between the sexes with some showing a female preponderance whilst some show it to be mostly amongst males [11, 13]. Risky sexual behaviour (multiple partners, unprotected sex) and lifestyle such as heavy alcohol intake more common in South African males than females might also explain the 
univariate association between male gender and Bell's palsy in this study [18].

\section{Seasons}

Previous studies on the relationship between seasons and Bell's palsy have had varied observations with some finding a clear association or seasonal clustering and yet others not finding any such connection. In a study of a 1000 patients with facial palsies, reporting on seasonal data between 1969 and 1973, no preference of occurrence was found between warm and cold climates [19]. This was echoed by a Danish study of 2500 patients with Bell's palsy [8]. Yet another study from Greece found no relation to the occurrence of Bell's palsy and weather [20]. A study of 1181 US soldiers with Bell's palsy however, revealed a clear increase in occurrence during the cold months as opposed to the warm seasons [21]. This is echoed by a Libyan study in the region of Benghazi where they also found clustering in the December and January months [3]. The proponents of clustering in the months of winter suggest that this could be linked to a flare up of the herpes (HSV-1), a virus which has been associated with Bell's palsy [21]. In Turkey, Bell's palsy was found to be more frequent in Spring with the nadir in winter [4]. The non-uniform manifestations of global seasons and possible confounding factors like atmospheric pressure and humidity could account for the varied findings. The seasonal cyclical occurrence of Bell's palsy demonstrated in the present study has never been described before.

\section{Possible mechanisms}

Patients seen at our hospital are from a poorer section of Pretoria, a social construct from Apartheid South Africa. The low socioeconomic status would carry stressors unique to this population. A link between psychological stress and the development of Bell's palsy has been described [22].

To our knowledge, this is the first study to demonstrate HIV infection, younger age and cold seasons as independent predictors of Bell's palsy among black South Africans. HIV infection is associated with oxidative stress affecting both the central and peripheral nervous systems (albeit with the latter being a result of some antiretroviral drug regimes) [23-25]. The excess free radicals formed lead to tissue injury with resultant impairment of function. Oxidative stress has also been described with the herpes group of viruses [26]. Furthermore, cold weather has also been associated with oxidative stress which is a possible reason for a surge in the occurrence of Bell's palsy during colder seasons [27]. The free radicals formed with oxidative stress lead to tissue damage and could possibly be a factor in accelerating incident Bell's palsy in these black South Africans.
HIV infection has been associated with lower levels of S-adenosylmethionine, the principal methyl donor in cytosine methylation metabolite important for transmethylation which is important for myelin formation [28]. Low levels of this metabolite can result in an aberrant DNA methylation pattern and development of neuropathies [29].

The extent to which nutrition played a role was not established in this population. Vitamin deficiencies have been described as a common co-existence with HIV infection in poorer communities resulting in neuropathies [30].

\section{Cognitive function in HIV positive Bell's palsy patients}

There were no cognitive deficits detected in our patients with Bell's palsy, including the HIV positive group. A literature search on HIV positive Bell's palsy and cognitive function did not yield results. Future studies with robust assessments for even mild cognitive changes in HIV positive Bell's palsy individuals could be of value. The high number of individuals in this study not on antiretroviral therapy is concerning. This however, would have improved post September 2016 with the introduction of the "test and treat" policy in South Africa [31]. The effect of antiretroviral therapy in HIV positive individuals has been shown not to grant absolutely protection of cognitive function. The reason for the latter finding is still a matter for research [32].

\section{Clinical implications and perspectives for public}

This study availed an opportunity for an improved understanding of incident Bell's palsy and its risk factors in the black African patient. Prevention strategies could possibly emanate from improved knowledge of Bell's palsy, a condition which continues to be regarded as idiopathic. Furthermore, efficacious and cost-effective treatment programmes will emerge from an in-depth understanding of Bell's palsy. Bell's palsy is also a possible outcome of psychological stressors linked with a poor socio-economic status prevalent amongst the studied population of black South Africans. Further studies on the latter are needed. Government legislation has since changed in South Africa, with much improvement in availability of ARV treatment.

\section{Conclusion}

Environmental factors by seasonality, younger age and HIV positivity are important and independent risk factors of Bell's palsy. Education and awareness programs on the possible effects of HIV and seasons on the development of Bell's palsy are necessary. A better understanding of this condition and its predictors could lead to well designed preventative measures amongst young black South Africans. 


\section{Abbreviations}

HIV: Human immunodeficiency virus; HSV: Herpes simplex virus; DNA: Deoxyribonucleic acid; HR: Hazard ratio; RR: Relative risk; Cl: Confidence interval; SPSS: Statistics package of social sciences; IBM: International business machines; US: United States

\section{Acknowledgements}

Not applicable.

\section{Authors' contributions}

DM: Corresponding author (Collected data, wrote article and analysed data). BL: Significant data analysis and supervised the writing. SM: Contributed to the writing of the article. $\mathrm{C}$ vd M: Contributed to the clinical aspects of the study (assessment of patients) and the writing. MN: Contributed significantly to the handling of data. MM: Contributed to the statistical analysis of the data. OT: Critiqued the article and made substantial contributions to the writing. ${ }^{* *}$ All authors read and approved the final manuscript.

\section{Funding}

No special funding was received.

\section{Availability of data and materials}

Data will be available on request to corresponding author.

\section{Ethics approval and consent to participate}

Ethics approval was granted by the Medical research council (MREC) of the university of Limpopo (Medunsa) - name has changed to Sefako Makgatho Health Sciences University, the clearance number: MREC/M/185/2012.

\section{Consent for publication}

Not applicable.

\section{Competing interests}

Not applicable.

\section{Author details}

'Department of Neurology, Sefako Makgatho Health Sciences University, Pretoria, South Africa. ${ }^{2}$ Department of Internal Medicine, University of Kinshasa, Kinshasa, Democratic Republic of Congo. ${ }^{3}$ Department of Paediatrics, Sefako Makgatho Health Sciences University, Pretoria, South Africa. ${ }^{4}$ Department of statistics, Tshwane University of technology, Pretoria, South Africa. ${ }^{5}$ Faculty of health Sciences, Walter Sisulu University, Mthatha, South Africa. ${ }^{6}$ Department of Internal Medicine, Sefako Makgatho Health Sciences University, Pretoria, South Africa.

\section{Received: 6 March 2020 Accepted: 16 October 2020}

\section{Published online: 21 October 2020}

\section{References}

1. Friedreich NA. De paralysis musculorum faciei rheumatica. J der Erfindungen (Gotha).1798; 8 (XXV). As quoted in Annals of Medicine (Edinburgh), 1800, 5, 214-226.

2. Ding HC, Wang RD, Mao TQ, Peng PQ. Biologic effects of freezing on tissues of the maxillofacial region. J Oral Maxillofac Surg. 1985;43(10):778-81.

3. Sridharan R, Radhakrishnan K, Ashok PP, Mousa ME. Clinical and epidemiological study of Bell's palsy in Benghazi, Libya. Afr J Med Med Sci. 1988;17(3):141-4.

4. Narcı H, Horasanlı B. M: seasonal effects on Bell's palsy: four-year study and review of the literature. Iran Red Crescent Med J. 2012:14(8):505-6.

5. Balogou AK, Kpemissi E, Nack-Nack M, Anani T, Agboli K, Prince DM, Grunitzky EK. Peripheral facial paralysis (PFP) and HIV infection in Togo. Acta Neurol Scand. 1998;98(3):200-3.

6. Belec L, Georges AJ, Bouree P, Schuller E, Vuillecard E, Di Costanzo B, Martin PM. Peripheral facial nerve palsy related to HIV infection: relationship with the immunological status and the HIV staging in Central Africa. Cent Afr J Med. 1991:37(3):88-93.

7. Casanova Sotolongo P, Casanova Carillo P. [Association of peripheral facial paralysis in patients with human immunodeficiency virus infection] in Spanish. Rev Neurol. 2001;32(4):327-30.

8. Peitersen E. Bell's palsy: the spontaneous course of 2,500 peripheral facial nerve palsies of different etiologies. Acta Otolaryngol Suppl. 2002;549:4-30.
9. Monini S, Lezzarino AL, Lacolucci C, Buffoni A, Barbara M. Epidemiology of Bell's palsy in an Italian Health District: Incidence and case-control study. Acta Otorhinolaryngolo Ital. 2010;30(40):198.

10. Zohrevandi B, Monsef Kasmaee V, Asadi P, Tajik H. Report of 121 cases of Bell's palsy referred to the emergency department. Emerg (Tehran). 2014; 2(2):66-70.

11. Zhao H, Zhang X, Tang YD, Zhu J, Wang XH, Li ST. Bell's palsy: clinical analysis of 372 cases and review of related literature. Eur Neurol. 2017;77(34):168-72.

12. Khedr EM, Fawi G, Abbas MA, El-Fetoh NA, Zaki AF, Gamea A. Prevalence of Bell's palsy in Qena governorate, Egypt. Neurol Res. 2016;38(8):663-8.

13. Nicoletti A, Sofia V, Bartoloni A, Bartalesi F, Marletta C, Lo Bartolo ML, Rosado J, Le Pira F, Reggio A. Lifetime prevalence of Bell's palsy in rural Bolivia: a door-to-door survey. Neuroepidemiology. 2002;21(2):100-4.

14. Komolafe MA, Fatusi OA, Alatesi OI, Komolafe EO, Amusa YB, Adeolu AA Durosinmi MA. The role of human immunodeficiency virus infection in infranuclear facial paralysis. J Natl Med Assoc. 2009;101(4):361-6.

15. Cirpaciu D, Goanta CM. Bell's palsy: data from a study of 70 cases. J Med Life. 2014; 7 Spec No. 2:24-28.

16. Valença MM, Valença LP, Lima MC. Idiopathic facial paralysis (Bell's palsy): a study of 180 patients. Arq Neurosiquiatr. 2001;59(3-B):733-9 Article in Portuguese.

17. Rowlands S, Hooper R, Hughes R, Burney P. The epidemiology and treatment of Bell's palsy in the UK. Eur J Neurol. 2002;9(1):63-7.

18. Manyaapelo T, Nyembezi A, Ruiter RA, Borne BV, Sifunda S, Reddy P. Understanding the psychosocial correlates of the intention to use condoms among young men in KwaZulu-Natal, South Africa. Int J Environ Res Public Health. 2017; 14(4). pii: E339.

19. Adour KK, Byl FM, Hilsinger RL Jr, Kahn ZM, Sheldon MI. The true nature of Bell's palsy: analysis of 1,000 consecutive patients. Laryngoscope. 1978;88: 787-801.

20. Danielides V, Patrikakos G, Nousia C-S, Bartzokas A, Milionis HJ, Lolis C, Skevas A. Weather conditions and Bell's palsy: five-year study and review of the literature. BMC Neurol. 2001;1:7.

21. Campbell KE, Brundage JF. Effects, latitude, and season on the incidence of Bell's palsy in the US armed forces, October 1997 to September 1999. Epidemiol. 2002;156:32-9.

22. Tseng CC, Hu LY, Liu ME, Yang AC, Shen CC, Tsai SJ. Bidirectional association between Bell's palsy and anxiety disorders: a nationwide population-based retrospective cohort study. J Affect Disord. 2017;215:269-73.

23. Price TO, Ercal N, Nakaoke R, Banks WA. HIV-1 viral proteins gp 120 and tat induse oxidative stress in brain endothelial cells. Brain Res. 2005:1045(1-2): 57-63.

24. Hulgan T, Hughes M, Sun X, Smeaton LM, Terry E, Robbins GK, Shafer RW, Clifford RB, McComsey GA, Canter JA, Morrow JD, Haas DW. Oxidative stress and peripheral neuropathy during antiretroviral therapy: an AIDS clinical trials group study. J Acquir Immune Defic Syndr. 2006;42(4):450-4.

25. Longo-Mbenza B, Longokolo Mashi M, Lelo Tshikwela M, Mokondjimobe $E_{\text {, }}$ Gombet T, Ellenga-Mbolla B, Nge Okwe A, Kangola Kabangu N, Mbungu FS. Relationship between younger age, autoimmunity, Cardiometabolic risk, oxidative stress, HAART, and ischemic stroke in Africans with HIV/AIDS. ISRN Cardiol. 2011;2011:897908.

26. Schachtele SJ, Hu S, Little MR, Lokensgard JR. Herpes simplex virus induces neural oxidative damage via microglial cell toll-like receptor-2. J Neuroinflammation. 2010;7:35.

27. Martarelli D, Cocchioni M, Scuri S, Spataro A, Pompei P. Cold exposure increases exercise-induced oxidative stress. J Sports Med Phys Fitness. 2011. 51(2):299-304

28. Di Rocco A, Bottiglieri T, Werner P, Geraci A, Simpson D, Godbold J, Morgello S. Abnormal cobalamin-dependent transmethylation in AIDSassociated myelopathy. Neurology. 2002:58(5):730-5.

29. Varela-Rey M, Iruarrizaga-Lejarreta M, Lozano JJ, Aransay AM, Fernandez AF, Lavin JL, Mósen-Ansorena D, Berdasco M, Turmaine M, Luka Z, Wagner C, Lu SC, Esteller M, Mirsky R, Jessen KR, Fraga MF, Martínez-Chantar ML, Mato JM, Woodhoo A. S-adenosylmethionine levels regulate the schwann cell DNA methylome. Neuron. 2014;81(5):1024-39.

30. Ndakala FN, Oyugi JO, Oluka MO. HIV-associated polyneuropathy in resource-limited settings: genetic predisposition and vitamin variations. World J AIDS. 2017;7:106-21.

31. Chihana ML, Huerga H, Van Cutsem G, Ellman T, Wanjala S, Masiku C, Szumilin E, Etard JF, Davies MA, Maman D. Impact of "test and treat" 
recommendations on eligibility for antiretroviral treatment: cross sectional population survey data from three high HIV prevalence countries. PLoS One. 2018;13(11):e0207656. https://doi.org/10.1371/journal.Pone.0207656.

32. Sanford R, Fellows LK, Ances BM, Collins DL. Association of Brain Structure

Changes and Cognitive Function with combination antiretroviral therapy in HIV-positive individuals. JAMA Neurol. 2018;75(1):72-9.

\section{Publisher's Note}

Springer Nature remains neutral with regard to jurisdictional claims in published maps and institutional affiliations.

Ready to submit your research? Choose BMC and benefit from:

- fast, convenient online submission

- thorough peer review by experienced researchers in your field

- rapid publication on acceptance

- support for research data, including large and complex data types

- gold Open Access which fosters wider collaboration and increased citations

- maximum visibility for your research: over $100 \mathrm{M}$ website views per year

At BMC, research is always in progress.

Learn more biomedcentral.com/submissions 